\title{
FREQUÊNCIA ESCOLAR E ENSINO REMOTO: DESAFIOS À EDUCAÇÃO EM TEMPOS DE PANDEMIA
}

\author{
School Attendance and Remote Education: Challenges to Education in Times of \\ Pandemic
}

\author{
Larissa Cavalcanti de Albuquerque ${ }^{1}$ \\ Ércules Laurentino Diniz ${ }^{2}$ \\ Edineide Jezini Mesquita de Araújo ${ }^{3}$ \\ Maria das Graças de Almeida Baptista ${ }^{4}$
}

\begin{abstract}
Resumo: A pandemia da Covid-19 impôs uma série de desafios à escola, sendo a frequência escolar um desses. A difícil tarefa consistiu em assegurar a continuidade dos estudos sem a possibilidade de acesso às escolas de forma presencial. Diante de tal cenário, o presente trabalho tem por objetivo avaliar o nível de participação dos estudantes a partir das atividades remotas durante o período de pandemia entre os meses de abril e dezembro de 2020. Para tanto, foram pesquisados os acessos de estudantes à plataforma Google Classroom durante 30 semanas de atividades remotas. Os estudantes pesquisados se encontram matriculados em turmas dos anos finais do Ensino Fundamental em uma escola situada no município de João Pessoa-PB. Tratase de uma pesquisa de cunho qualitativo e de caráter descritivo. Conclui-se que, em um contexto de vulnerabilidade social, embora as propostas tecnológicas apresentadas pela escola sejam muito importantes para a garantia da continuidade dos estudos, elas não se constituem opção para muitos estudantes que se encontram destituídos do processo de inclusão digital. Acreditamos que as propostas para o pós-pandemia devem ser elaboradas levando em
\end{abstract}

\footnotetext{
${ }^{1}$ Mestra pelo Programa de Pós-Graduação em Educação da Universidade Federal da Paraíba (2017). Especialista em Gestão Pública Municipal pela Universidade Estadual da Paraíba (2015). Graduada em Serviço Social pela Universidade Federal da Paraíba (2011). Assistente social na rede municipal de João Pessoa-PB. Orcid: https://orcid.org/0000-0001-8439-3195. E-mail: laalbuquerque13@ hotmail.com
}

\footnotetext{
${ }^{2}$ Mestre pelo Programa de Pós-Graduação em Educação da Universidade Federal da Paraíba (2018). Especialista em Fundamentos da Educação: práticas pedagógicas interdisciplinares pela Universidade Estadual da Paraíba (2014). Bacharel e Licenciado em Ciências Biológicas pela Universidade Federal da Paraíba (2011). Professor na rede estadual da Paraíba. Orcid: https://orcid.org/0000-0003-4932-8915. E-mail: ercules.diniz@ hotmail.com

${ }^{3}$ Possui Graduação em Pedagogia pela Universidade Federal do Amazonas (1988), Mestrado em Educação pela Universidade Federal da Paraíba (1997), Doutorado em Sociologia pela Universidade Federal de Pernambuco (2002) e Pós-doutoramento na Universidade Lusófona de Humanidades e Tecnologias - Lisboa/PT (CAPES/FCT), com instância acadêmica na Universidade de Valência (Espanha, 2011). Professora Titular da Universidade Federal da Paraíba com atuação no ensino, pesquisa e extensão, na Graduação e Pós-graduação. Orcid: https://orcid.org/0000-0002-0180-0347. E-mail: edjezine@ gmail.com

${ }^{4}$ Possui Pós-doutorado em Educação pela Universidade Estadual de Campinas (UNICAMP), Doutora e Mestre em Educação pelo Programa de Pós-graduação em Educação da Universidade Federal da Paraíba (PPGE/UFPB) e Psicóloga e Licenciada em Psicologia pela Universidade Federal Fluminense (UFF). Professora do Programa de Pós-graduação em Educação (PPGE/UFPB) na Linha de Pesquisa Processos de Ensino-Aprendizagem e do Departamento de Fundamentação da Educação do Centro de Educação (UFPB) na área de Psicologia da Educação. Orcid: https://orcid.org/0000-0003-1084-4269. E-mail: gabaptista2@yahoo.com.br
} 
consideração resultados como os apresentados no presente artigo, sem os quais as respostas ao problema serão inócuas para a vida de grande parte dos estudantes brasileiros.

Palavras-chave: Ensino Remoto. Pandemia. Frequência escolar.

\begin{abstract}
The COVID-19 pandemic imposed a series of challenges on the school, with school attendance being one of those. The difficult task was to ensure continuity of studies without the possibility of accessing schools in person. In view of this scenario, the present study aims to assess the level of student participation from remote activities during the pandemic period between April and December 2020. To do so, student accesses to the Google platform during 30 weeks of remote activities were surveyed. The researched students are enrolled in classes of the final years of elementary school in a school located in the city of João Pessoa-PB. It is concluded that, in a context of social vulnerability, although the technological proposals presented by the school are very important to guarantee the continuity of studies, they are not an option for many students who are deprived of the digital inclusion process. We believe that proposals for the post-pandemic should be developed taking into account results such as those presented in this article, without which, the answers to the problem will be innocuous for the lives of a large part of Brazilian students.
\end{abstract}

Keywords: Remote Education. Pandemic. School frequency.

\title{
1 Introdução
}

A pandemia da Covid-19, ao impossibilitar o ensino nas dependências escolares, impeliu toda a equipe escolar a um processo de transição dos ambientes físicos para os virtuais, e tal migração entre estes espaços não se apresenta como uma tarefa de fácil execução, principalmente quando o tempo é exíguo.

Não poderíamos imaginar que, em 2020, o mundo teria que enfrentar uma pandemia e que esta faria grandes potências mundiais sofrerem abalos econômicos. Não bastassem os efeitos na saúde, com indivíduos acometidos pelo coronavírus, e na economia, com perda de renda e aumento de desemprego, a medida tomada pelas redes de educação do Brasil, bem como do estado da Paraíba, foi o fechamento das escolas, como forma de diminuir as possibilidades de contágio pela Covid-19, e a adoção do ensino remoto para a continuidade das aulas.

Assim, conforme apontam Morgado, Sousa e Pacheco (2020, p. 04): “Trata-se de uma situação de risco, neste momento apenas contornável através de um efetivo isolamento físico e da ausência de contato com eventuais portadores do vírus, o que gera uma enorme sensação de desconfiança e incerteza [...]". Incerteza e medo que permeiam as relações tanto do tempo presente como do futuro próximo, de tal modo que há uma clara necessidade de adequação da educação, principalmente porque este será um dos setores em que haverá maior transformação no mundo pós-pandemia.

Quanto ao trabalho remoto, a transição dos ambientes físicos para os ambientes virtuais de aprendizagem teve fundamental participação do Governo do Estado da Paraíba por meio da implantação do sistema de gerenciamento de conteúdos para escolas, o Google Classroom. Dentre as várias ferramentas disponibilizadas pela plataforma, como postagem de vídeo, tarefas individuais ou em grupos e encontros pelo Meet, há aquelas que possibilitam interações assíncronas (emissor e receptor não se comunicam simultaneamente) e aquelas que possibilitam interações síncronas (emissor e receptor se comunicam simultaneamente). 
No universo das interações síncronas, a ferramenta Google Meet é uma das mais eficientes. A partir dela, professores e estudantes podem estabelecer uma comunicação simultânea, sendo possível o compartilhamento de mensagens e vídeos, a exposição de slides e a observação das reações de ambos os envolvidos nas interações, visto ser possível acompanhar suas expressões via webcam. Toda essa atmosfera criada auxilia na exposição de conteúdos, nas trocas de saberes, e atende ao anseio dos estudantes de terem as dúvidas sanadas instantaneamente.

A possibilidade de postar conteúdos e atividades diariamente, a fim de que os estudantes acompanhem os itinerários formativos de cada disciplina, também é um benefício conferido pela plataforma em questão e que consegue, na medida do possível, dirimir os efeitos da ausência de aulas presenciais. Nesse sentido, os conteúdos devem ser apresentados de forma mais objetiva e sucinta, e carecem de uma exposição com a linguagem mais dialógica possível.

Contudo, mesmo com todas as potencialidades inerentes aos recursos tecnológicos, quando levadas ao campo pedagógico, não é possível afirmar que as atividades desenvolvidas lograram completo êxito, principalmente do ponto de vista do acesso dos alunos. Vamos notar, no decorrer do artigo, que, nas turmas em que foi feita a pesquisa em tela, um número considerável de estudantes só foi alcançado ao longo de todo o período de ensino remoto por meio de atividades impressas.

Diante de tal cenário, o presente trabalho tem por objetivo avaliar a frequência escolar dos estudantes a partir das atividades remotas durante o período de pandemia entre os meses de abril e dezembro de 2020. Como objetivos específicos, citam-se: diagnosticar a participação dos discentes em cada turma; observar as relações entre o contexto social e a adesão ao ensino remoto; e investigar as metodologias que obtiveram êxito ao longo do período de ensino remoto emergencial. Trata-se de uma pesquisa de cunho qualitativo e de caráter descritivo.

\section{Pressupostos teóricos}

Uma das primeiras constatações que fizemos perante o contexto em que o ensino remoto surge como única solução foi a de que estava ocorrendo um equívoco em considerá-lo como sendo sinônimo de Educação a Distância. Embora as duas maneiras de propiciar aprendizagem dispensem a presença física dos docentes e discentes, a segunda é uma modalidade bastante consolidada e que difere do ensino remoto.

No Brasil, a Educação a Distância ocupa cada vez mais espaços. Temos, como nos lembra Valente (2011, p. 48), "modelos de EaD muito interessantes, diversificados e cada vez mais sólidos". Seja no Ensino Superior, na educação de nível técnico, em cursos de formação continuada ou em campos mais específicos, como o da formação de professores, essa modalidade representa para alguns brasileiros a única oportunidade, por exemplo, de ingressar em uma instituição de Ensino Superior.

Maria Luiza Belloni, logo no capítulo introdutório de uma das mais importantes referências bibliográficas que versam sobre a modalidade em questão, afirma que a Educação a Distância se apresenta como "desejável para atender às novas demandas educacionais decorrentes das mudanças na nova ordem econômica mundial” (BELLONI, 2015, p. 1).

É importante ressaltar que os sujeitos que buscam a Educação a Distância o fazem por escolhas de ordem pessoal, social ou econômica (MOORE; KEARSLEY, 2013). Opta-se por essa forma de educação compreendendo que estudantes que a ela aderem devem possuir acesso à internet e a recursos tecnológicos; do contrário, estarão impossibilitados de desenvolver suas 


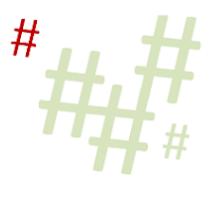

respectivas trajetórias acadêmicas. Imagina-se, também, que exista uma organização para o acompanhamento das aulas por parte dos discentes, que podem contar com polos de apoio presencial, materiais didáticos organizados de maneira sucinta com os principais pontos da disciplina, além de tutores, tanto on-line como presenciais, personagens centrais no que se refere ao auxílio pedagógico oferecido aos estudantes.

Sem dúvidas, o cenário vivenciado pelos nossos estudantes é bastante diverso do exposto acima. Sendo emergencial, o ensino remoto passou a ser desenvolvido sem o adequado tempo para criação de estruturas que assegurassem todo o aparato necessário e sem, muito menos, a indispensável mudança de postura de todos os envolvidos que atuam em sala de aulas físicas (ALBUQUERQUE et al., 2021) e que forçadamente tiveram que encaminhar a sua prática para os ambientes virtuais de aprendizagem, sendo este um desafio de grau ainda mais elevado.

O ensino remoto se mostrou uma alternativa para a continuidade das aulas, como meio de garantir o mínimo de acesso à escola e aos componentes curriculares, no intuito de não deixar os estudantes sem acesso ao saber sistematizado. Behar (2020) deixa claro que o ensino remoto emergencial (ERE), como modalidade de ensino que implica o distanciamento geográfico de docentes e alunos, foi adotado de forma temporária nos distintos níveis de ensino por instituições educacionais do mundo inteiro, para que as atividades escolares não fossem cessadas. Tal definição apresenta semelhanças com a apresentada a seguir - uma das mais completas que versam sobre a Educação a Distância; diverge, contudo, em um ponto principal, a saber: a sistematização das atividades.

Considera-se educação [a] distância a modalidade educacional na qual a mediação didático-pedagógica nos processos de ensino e aprendizagem ocorra com a utilização de meios e tecnologias de informação e comunicação, com pessoal qualificado, com políticas de acesso, com acompanhamento e avaliação compatíveis, entre outros, e desenvolva atividades educativas por estudantes e profissionais da educação que estejam em lugares e tempos diversos. (BRASIL, 2017, p. 02).

A rigor, tanto a Educação a Distância como o ensino remoto dispensam a presença física, sendo esse um ponto crucial para analisar as questões educacionais em tempos de pandemia. Visto que estamos em um país onde a escola representa o espaço mais importante para o acesso ao saber sistematizado, um espaço que deve se constituir sempre como uma forma de superação do pragmatismo da vida cotidiana (ANJOS, 2020), é fundamental a presença de todos os envolvidos no desenvolvimento dos processos de ensino-aprendizagem, inclusive quando os estudantes em questão estão matriculados no Ensino Fundamental.

Logo nos primeiros instantes em que os sistemas educacionais perceberam a necessidade de agir diante do cenário imposto pela pandemia, é provável que os mais entusiasmados apreciadores das tecnologias digitais tenham contemplado um excelente cenário, não pelos dados catastróficos da pandemia, mas pelos caminhos que se abriam para que as tecnologias ocupassem ainda mais espaço no campo pedagógico. Todavia, lembra-nos Andrade (2021, p. 16), "garantir o acesso às plataformas digitais não certificará o êxito das aprendizagens"; faz-se necessária a adequação às novas formas de aprendizagem.

Outro aspecto importante a ser destacado diz respeito ao público atendido pela modalidade a distância. Na maioria dos casos, trata-se de adultos, uma vez que "essa espécie de aprendizagem, que se dá em qualquer lugar e a qualquer hora, permite-lhes continuar trabalhando" (PALLOFF; PRATT, 2004, p. 23), sendo a flexibilidade uma das razões apontadas pelos alunos quando indagados sobre o porquê estudar a distância. 
Moore e Kearsley (2013) nos lembram que, nos Estados Unidos, a maioria dos estudantes da modalidade de Ensino a Distância está na faixa etária dos 25 aos 50 anos, e apontam as principais características inerentes aos adultos nesse processo: adultos gostam de ter o controle sobre o que está acontecendo; preferem definir o que querem aprender; prezam por tomar decisões sozinhos; têm prazer em usar as suas experiências como recurso de aprendizado.

É evidente, portanto, que inserir crianças e adolescentes em um processo de aprendizagem que dispensa a presença física dos envolvidos constitui um considerável desafio. Acostumados ao ensino presencial e não dispondo das características elencadas acima, os estudantes em idade escolar não podem simplesmente ser transferidos das salas de aulas físicas para os ambientes virtuais.

Para muitas escolas, restringir suas ações às plataformas digitais seria excluir um número considerável de seus estudantes dos processos pedagógicos. Sendo assim, atividades impressas a serem entregues nas residências dos estudantes ou obtidas em suas respectivas escolas foram imprescindíveis para que inúmeros sujeitos, já excluídos do universo digital, não fossem excluídos uma segunda vez.

O problema da exclusão digital não é, de forma alguma, novo. O Brasil continua sendo um país com índices significativos de desigualdade econômica e, em tempos de tecnologias digitais, a impossibilidade de utilizá-las implica sérios prejuízos, como muito bem apontado por Fadanelli e Porto (2020, p. 241):

\begin{abstract}
Os mais vulneráveis economicamente são os que continuam a estar fora do arsenal de conhecimentos novos, de discussões científicas e fundamentadas, de informações atualizadas, de possibilidades de interações com está no outro lado do mundo, de construção de novos saberes por meio de ferramentas digitais, por exemplo. Enfim, as condições sociais menos favorecidas fortalecem a exclusão digital, e com isso se alimenta o tradicional modelo social pautado nas divisões de classe e nas relações de poder verticalizadas. A exclusão digital torna-se, nesse ínterim, apenas mais um elemento de ampliação da exclusão social (FADANELLI; PORTO, 2020, p. 241).
\end{abstract}

Ainda acerca da exclusão, mais especificamente no contexto da pandemia, Castro (2020, p. 11) afirma que "esses indivíduos foram fadados a uma das formas de inexistência social, dado que torna impenetrável o sistema de ensino para quem não possui equipamento ou conexão". Sendo assim, o sistema se mostra ainda mais perverso em um quadro como o atual, em que um grupo de estudantes precisa se adaptar às novas formas de aprendizagem sem que haja tempo adequado; outro grupo nem ao menos pode se adequar, uma vez que se encontra totalmente destituído do processo, sendo composto por elementos invisíveis em uma época em que a presença virtual se mostrou compulsória.

\title{
3 Aspectos metodológicos
}

A Escola Estadual de Ensino Fundamental Ana Higina fica situada no bairro do Roger, município de João Pessoa - Paraíba. Localizada em uma área de vulnerabilidade social, a escola enfrenta grandes desafios; o maior deles talvez seja a garantia da frequência escolar em tempos de ensino remoto, diante de um contexto de privações das famílias dos estudantes, como desemprego e falta de acesso à internet. 
O estudante matriculado é, de maneira geral, filho da classe trabalhadora e não dispõe de muitos recursos em seu cotidiano, tendo a escola como instituição fundamental no processo de obtenção de conhecimentos que possibilitem, futuramente, o acesso ao mercado de trabalho. A presença da escola é, portanto, a materialização do Estado que cuida, educa e que, consequentemente, aumenta as possibilidades de mobilidade social no contexto supracitado.

O bairro do Roger é apresentado por Campos (2008, p. 94) como "um dos mais importantes e visados bairros da capital paraibana, até porque recebe os marcos como o antigo lixão, o presídio e a bica", sendo possível perceber que, enquanto o último dos marcos - um parque zoobotânico - constitui uma excelente referência, principalmente do ponto de vista da conservação da biodiversidade e do lazer, os dois primeiros conferem ao bairro um estigma bastante negativo.

Trata-se de uma pesquisa de cunho qualitativo e de caráter descritivo em que foram pesquisados os acessos de estudantes de cinco turmas da escola em questão. Para Marconi e Lakatos (2011, p. 269), "a metodologia qualitativa preocupa-se em analisar e interpretar aspectos mais profundos, descrevendo a complexidade do comportamento humano", sendo justamente esse o nosso alvo nesta pesquisa.

Entre os procedimentos metodológicos, estão o acompanhamento dos acessos dos

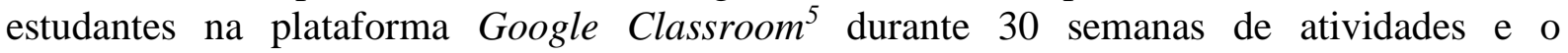
levantamento teórico sobre os trabalhos que versam sobre a aprendizagem que ocorre a partir dos ambientes virtuais.

Sendo um dos autores, docente da escola em questão, tivemos acesso à participação dos estudantes em todas as disciplinas durante o período vigente. O professor em questão, além de postar as atividades semanalmente e ministrar aulas diariamente, teve oportunidade de acompanhar a frequência de acessos dos estudantes para fins avaliativos e, principalmente, para utilizar as informações em questão no contexto de elaboração de estratégias da equipe escolar com vistas a superar as dificuldades advindas com a pandemia.

Os estudos de caráter descritivo são, de acordo com Triviños (2015, p. 110), bastante utilizados no campo da educação, e têm como foco essencial o "desejo de conhecer a comunidade, seus traços característicos, suas gentes, seus problemas, suas escolas [...]", sendo, em alguns casos, reconhecidos como estudos de caso em que essa descrição se torna mais aprofundada e se encontra debruçada sobre um fenômeno mais específico.

No presente estudo, o fenômeno em questão é a frequência escolar de estudantes atendidos pelo ensino remoto em tempo de pandemia. Cientes de que os resultados aqui apresentados não são passíveis de generalização, a validade do estudo reside no fato de que as reflexões podem ser utilizadas no âmbito da elaboração de desenvolvimento de atividades para o pós-pandemia, a exemplo da transição do ensino remoto para o ensino híbrido.

Os dados foram coletados a partir do acesso à sala virtual hospedada na plataforma Google Classroom, em que fora possível contemplar todas as participações dos estudantes ao longo das 30 semanas em todas as disciplinas ofertadas pela escola.

A fim de apontarmos as contradições de um processo que, no intuito de incluir estudantes nas práticas pedagógicas remotas, promove a exclusão de outros tantos (sem acessos às tecnologias), valemo-nos do materialismo histórico dialético, uma fundamentação teórico-

\footnotetext{
${ }^{5}$ Os dados foram obtidos sob autorização da gestão escolar. Os sujeitos não foram entrevistados e, portanto, não houve riscos de constrangimento ou intimidação, sendo alvo da pesquisa apenas os dados disponíveis na plataforma Google classroom.
} 
metodológica baseada nas ideias de Karl Marx e que, segundo Netto (2011), tem a realidade concreta como base, a partir da qual são feitas as abstrações e que se torna fundamental para analisarmos fenômenos que apresentam íntima relação com as questões socioeconômicas.

É justamente por concordarmos que "as concepções, os conceitos, as abstrações são elaborações empreendidas na esfera do pensamento a partir da atuação na realidade" (MASCARENHAS, 2014, p. 178), que não acreditamos ser possível analisar os dados aqui apresentados com uma objetividade que ignora as contradições reais. Estando a escola alvo da pesquisa situada em um contexto de vulnerabilidade social, não podemos nos ater aos dados alcançados sem que sejam contempladas as desigualdades econômicas das quais são vítimas os sujeitos que residem na localidade em questão.

Netto (2011, p. 25) nos adverte que, segundo Marx, no processo de pesquisa, "o papel do sujeito é essencialmente ativo: precisamente para apreender não a aparência ou a forma dada ao objeto, mas a sua essência". Nos moldes dessa pesquisa, o pesquisador se encontra em uma relação com o objeto completamente diferente dos modelos objetivista (supremacia do objeto) e subjetivista (supremacia do sujeito); aqui, segundo Guedin e Franco (2011), há o privilégio da historicidade dos fenômenos, considera-se o homem um ser ao mesmo tempo social e histórico e o critério de verdade se encontra na prática social.

\section{Resultados}

O levantamento feito a partir da plataforma expõe a frequência escolar de cinco turmas, todas elas com estudantes da segunda fase do Ensino Fundamental. Os dados são relativos aos acessos dos estudantes à plataforma Google Classroom durante 30 semanas de atividades, sendo estas desenvolvidas entre os meses de abril e dezembro do ano de 2020.

Tendo em vista a conexão que fizemos entre a Educação a Distância e o público adulto, precisamos lembrar que, aqui, estamos nos referindo a adolescentes, que se encontram numa fase de muitas mudanças e transições, sendo o aluno protagonista de rupturas, transformações de estilo, linguagem, postura e valores. Essa fase representa um momento ímpar de síntese ou organização interna de sentidos (MENEZES, 2003).

É importante observar que os acessos apresentados nos gráficos a seguir podem ter sido realizados pelo mesmo estudante em mais de uma ocasião, fato que explica o motivo pelo qual, em alguns casos, o número de acessos é superior ao de estudantes matriculados. Quanto a esses números, a turma do $6^{\circ}$ ANO A apresentava 25 alunos; a do $6^{\circ}$ ANO B, 22 alunos; a do $7^{\circ}$ ANO, 21 alunos; a do $8^{\circ}$ ANO, 28 alunos; e a do $9^{\circ}$ ANO, 18 alunos.

Do total de 114 alunos matriculados nas cinco turmas, caso a escola não tivesse apresentado outras alternativas à plataforma on-line, apenas 55 estudantes teriam sido contemplados pelas atividades desenvolvidas ao longo dos oito meses em que foram pesquisados os acessos.

Relata-se $48 \%$ de estudantes que tiveram condições de acessar as atividades apenas a partir dos meios eletrônicos, incluindo as atividades postadas na plataforma e as aulas síncronas via Google Meet. Os demais foram contemplados ou a partir de atividades on-line em períodos em que podiam contar com acesso à internet, mescladas com as atividades impressas, ou única e exclusivamente por meio de atividades impressas.

É importante lembrar que a problemática tanto do acesso quanto à permanência na escola é anterior à pandemia causada pela Covid-19, conforme podemos observar nos dados da Pesquisa Nacional de Amostra de Domicílios. Em 2018, 47,4\% das pessoas de 25 anos ou mais 
haviam completado a Educação Básica obrigatória; assim, 52,6\% não chegaram a concluir o Ensino Médio - o equivalente a 70,3 milhões de pessoas (IBGE, 2019). Contudo, os obstáculos impostos atualmente deixam o cenário ainda mais caótico, de modo que o futuro que ora se desenha se mostra ainda mais desafiador.

A tabela 1 expõe os números de estudantes atendidos ao longo das 30 semanas a partir dos meios eletrônico, eletrônico/impresso (simultaneamente), e apenas impresso, sendo possível identificar que, em todas as turmas, houve a necessidade de atendimento impresso, sendo este superior ao eletrônico em uma delas.

Chegamos, portanto, ao fim dos oito meses de acesso, com $22 \%$ dos estudantes sendo acessados por meio eletrônico e impresso simultaneamente e 30\% dos estudantes sendo contemplados pelas atividades impressas. Dessa forma, é possível perceber que esses números somados superam o de estudantes que tiveram o "privilégio" de desenvolver todas as suas atividades a partir da plataforma on-line.

Tabela 1 - Forma de atendimento dos estudantes

\begin{tabular}{cccc}
\hline TURMAS & $\begin{array}{c}\text { Atendimento apenas } \\
\text { por meio eletrônico }\end{array}$ & $\begin{array}{c}\text { Atendimento por meio } \\
\text { eletrônico e impresso }\end{array}$ & $\begin{array}{c}\text { Atendimento apenas por meio } \\
\text { impresso }\end{array}$ \\
\hline $6^{\circ}$ ANO A & 11 & 6 & 8 \\
$6^{\circ}$ ANO B & 1 & 8 & 13 \\
$7^{\circ}$ ANO & 14 & 4 & 3 \\
$8^{\circ}$ ANO & 14 & 5 & 9 \\
$9^{\circ}$ ANO & 15 & 2 & 1 \\
\hline
\end{tabular}

Ao observarmos os dados referentes aos acessos à plataforma Google Classroom, constatamos o tamanho do desafio que fora assegurar aos estudantes a devida instrução em tempos de pandemia. Em todas as turmas, os dados evidenciam uma queda desses acessos ao longo das 30 semanas. Até mesmo as turmas inicialmente mais participativas não mantiveram o mesmo grau de adesão ao longo dos oito meses em que tiveram que desenvolver todas as atividades a partir da plataforma.

O acesso e a permanência dos alunos na escola estão relacionados a fatores extraescolares, mas também intraescolares. Conforme Branco et al. (2020, p. 137):

[...] a primeira relaciona-se aos fatores externos à escola como, por exemplo, a relação familiar, as desigualdades sociais, a violência, a necessidade de trabalhar, as drogas, entre outros; a segunda abordagem diz respeito aos fatores internos, tais como: infraestrutura escolar precária, necessidades de formação inicial e continuada dos professores, possíveis desajustes na prática didático-metodológica, desmotivação, gestão autoritária, falta de identidade do aluno com a escola.

Contudo, no contexto atual, acesso e permanência são índices que dependem muito mais de fatores extraescolares, uma vez que, não podendo adentrar o espaço escolar, é a realidade imediata dos estudantes que vai determinar o seu nível de participação nas atividades remotas. 
No Gráfico 1, os números que apontam um índice superior aos 25 acessos nas primeiras semanas não alcançam cinco nas últimas; no Gráfico 2, que expõe a participação de outra turma, é possível contemplar que o número de entradas na plataforma é baixo desde o início, sendo o índice de sete acessos atingido apenas durante a semana 21.

Quando observamos os Gráficos 3 e 4, atentamos para uma frequência de acessos um pouco melhor, mas ainda muito aquém do esperado. Apenas em sete semanas, o número de acessos foi superior a cinco, tratando-se, portanto, de um dado preocupante, levando em consideração o total de 30 semanas pesquisadas.

O melhor desempenho foi contemplado no Gráfico 5, havendo para isso uma razão principal. A turma em questão é composta por estudantes com uma faixa etária mais elevada (entre 14 e 15 anos), quando comparada à dos estudantes das demais turmas. Longe de ser um desempenho ideal, o número de acessos foi bastante significativo, bem como a frequência obtida.

Gráfico 1 - Estimativa de acessos dos estudantes do $6^{\circ}$ ANO A

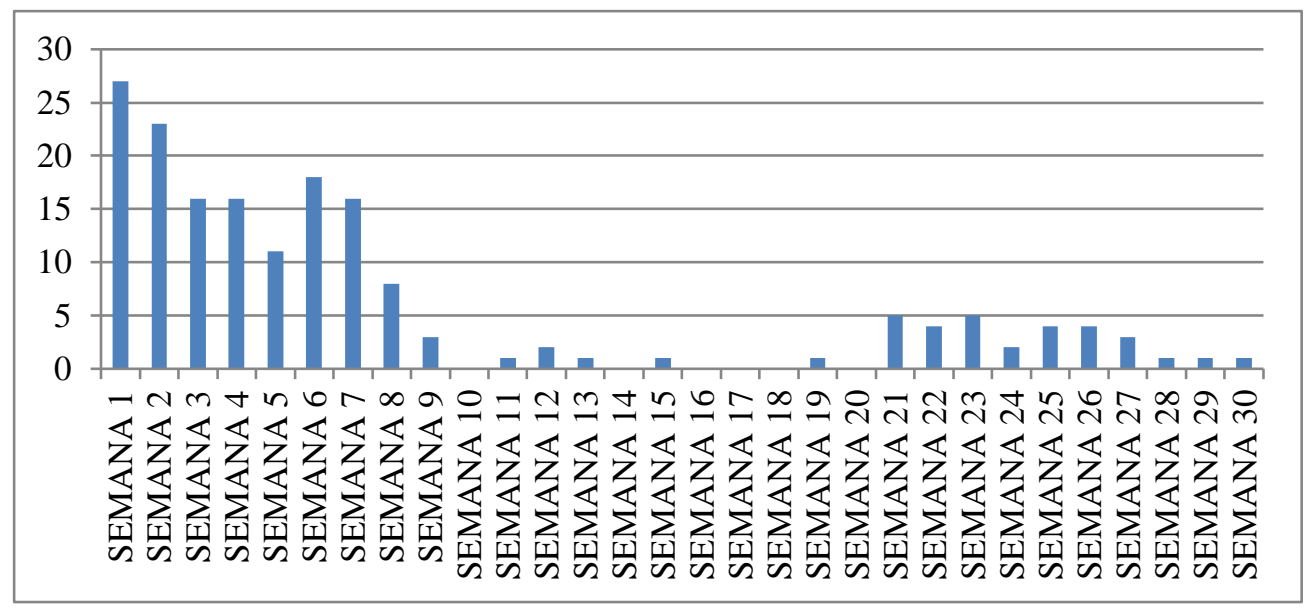

Fonte: Elaborada pelos autores (2021).

Os desafios são, portanto, inúmeros: falta de computadores e de internet, e a própria impossibilidade de ter um local adequado para estudos em uma casa onde, se estiverem sendo obedecidas as regras do distanciamento social, os moradores estão ficando em casa por mais tempo que o habitual. Trata-se de um cenário muito bem apresentado por Paulo, Araújo e Oliveira (2020, p. 197):

É notável que o atual momento consiga unir a sociedade por uma grande semelhança, a de que estão igualmente ameaçados pelo vírus do Covid-19 e por outro lado, distanciá-la fisicamente, ante os riscos da doença e das suas consequências. $\mathrm{O}$ receio do retorno presencial das aulas e a preocupação quanto à possibilidade de perda do ano letivo, a ausência de uma vacina, insuficiência de informações sobre o Covid-19 e a sua alta taxa de contágio, geraram a necessidade do ensino remoto emergencial. Tal ensino segue como uma opção razoável para a ocasião, mas não está isento de inúmeras tribulações, dentre as quais, a falta de aparelhos e boa conexão por parte de vários alunos e professores, ansiedade, acúmulo de trabalho, evasão, entre outros (PAULO; ARAÚJO; OLIVEIRA, 2020, p. 197). 
É muito importante ressaltar o esforço empreendido pelos professores (as) na tentativa de dirimir as consequências impostas pelo momento. Além dos acessos assíncronos ao google classroom, também ocorreram aulas assíncronas, encaminhamento de materiais impressos, desenvolvimento de lives com possibilidade de interação. Contudo, o fato de as aulas iniciais serem aquelas com maior frequência de acesso, leva-nos à conclusão de que, adaptados ao ensino presencial, os estudantes não conseguiram se adequar ao desenvolvimento de atividades à distância por um período de tempo mais extenso.

Gráfico 2 - Estimativa de acessos dos estudantes do $6^{\circ}$ ANO B

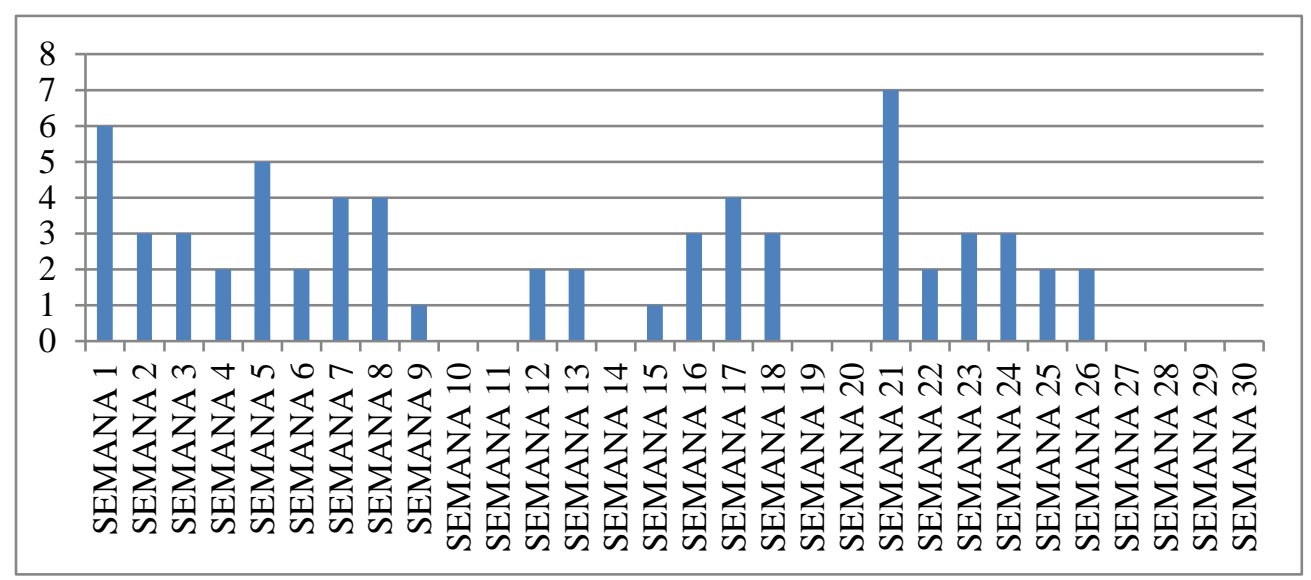

Fonte: Elaborada pelos autores (2021).

Gráfico 3 - Estimativa de acessos dos estudantes do $7^{\circ}$ ANO

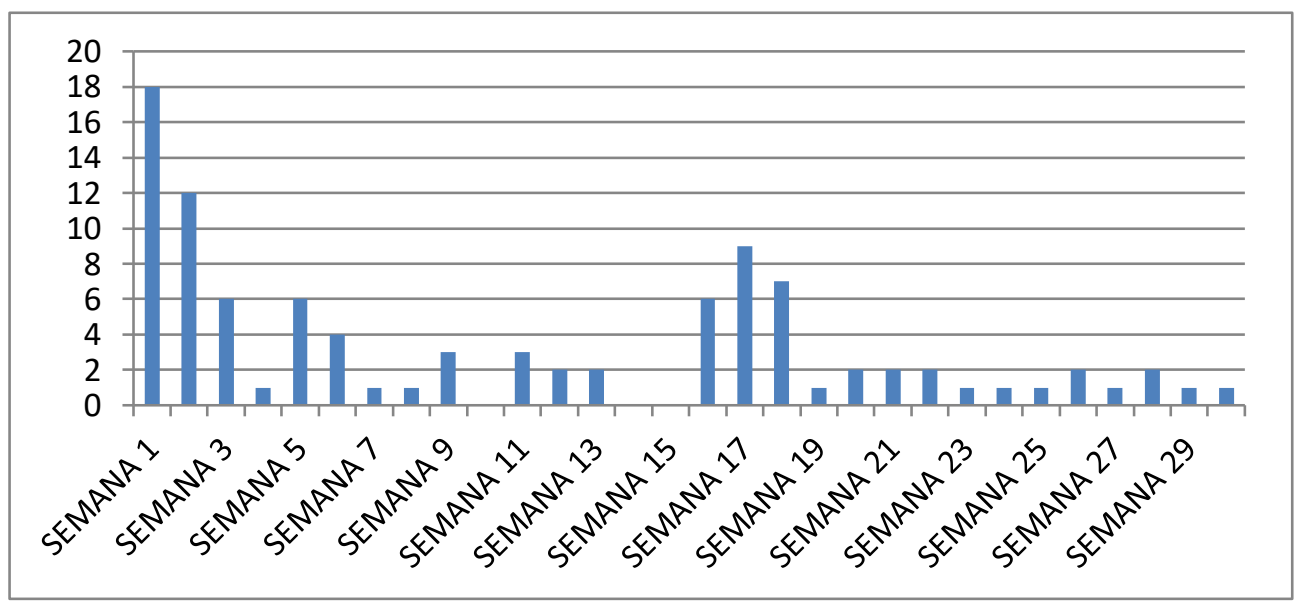

Fonte: Elaborada pelos autores (2021).

Outra hipótese para a diminuição dos acessos com o passar dos meses diz respeito à necessidade de muitos pais precisarem trabalhar. Por vezes, é a sobrevivência da família que está em questão, diante do irrisório valor do auxílio emergencial, de seu corte ou até mesmo do não acesso ao auxílio. Tudo isso constitui motivações para a busca de trabalhos informais tendo em vista a complementação de renda. Dessa forma, os pais apresentam dificuldades em orientar e acompanhar as atividades escolares, fenômeno causado também por sua própria baixa escolaridade. Segundo Bezerra et al. (2020, p. 6): 
Existe uma discussão na mídia e no senso comum que a parcela com menor renda está praticando menos o isolamento social em relação à parcela com maior renda, principalmente em função da necessidade de locomoção para o trabalho, uma vez que a população mais pobre está vinculada a atividades essenciais que não pararam, e a população com maior renda está, de forma geral, mais vinculada às atividades que pararam e/ou estabeleceram o trabalho remoto (BEZERRA et al., 2020, p. 6).

Gráfico 4 - Estimativa de acessos dos estudantes do $8^{\circ}$ ANO

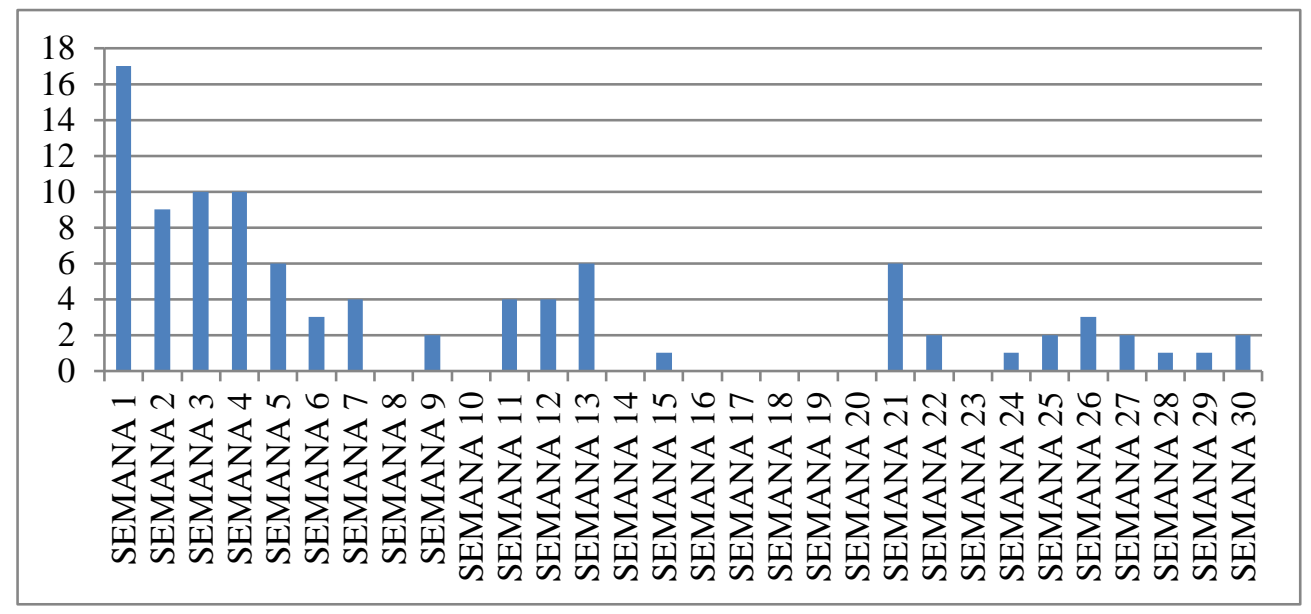

Fonte: Elaborada pelos autores (2021).

Gráfico 5 - Estimativa de acessos dos estudantes do $9^{\circ}$ ANO

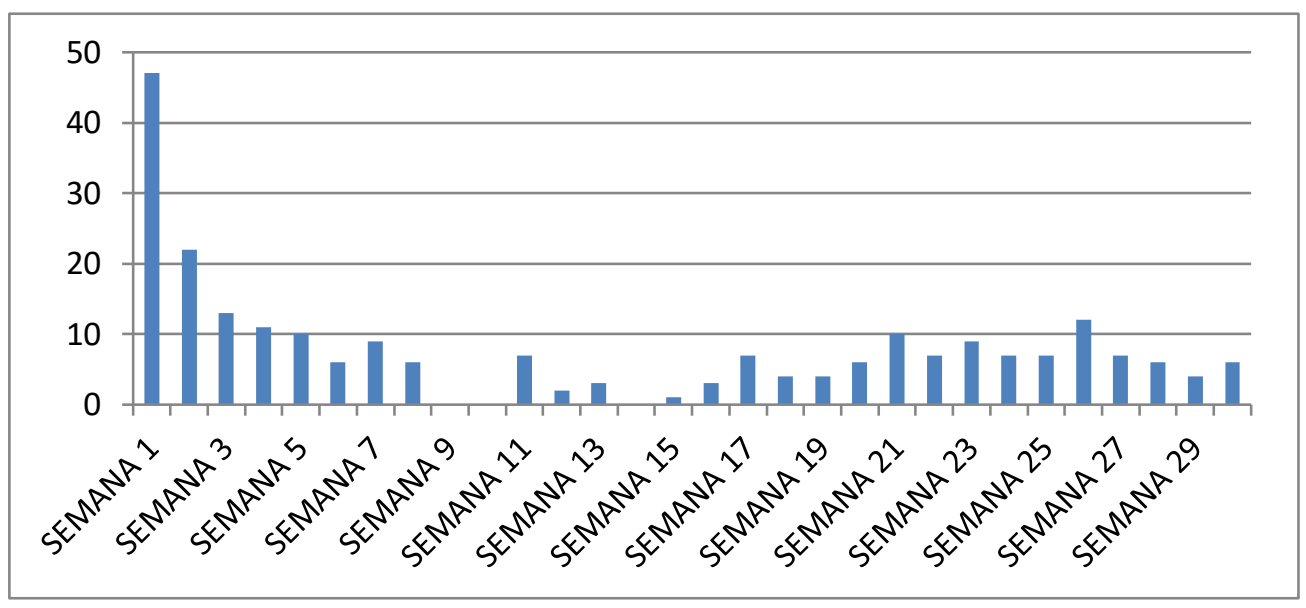

Fonte: Elaborada pelos autores (2021).

É importante lembrarmos que, do ponto de vista dos docentes, os desafios também são imensos: gravações, produção e edição de vídeos; cursos para atualização; aulas síncronas e assíncronas; elaboração de materiais adequados ao ensino remoto; responsabilidade para com as questões burocráticas. Candau (2014) afirma que, no tocante à atividade de ser professor, esta já vinha se transformando em uma atividade que implica vários desafios, como resistência, saúde e equilíbrio emocional, habilidade de enfrentar conflitos e construir vivências pedagógicas significativas; contudo, reconhecemos que a atuação no contexto atual representou a potencialização de todos esses fatores. 
A pandemia lançou holofote nas desigualdades já presentes há muito tempo em nosso país e o ensino remoto entra nesse contexto como alternativa viável para prosseguir com o processo ensino-aprendizagem, mas com pouca possibilidade de êxito em alguns contextos, justamente pelas desigualdades supracitadas. Para mantermos a esperança de que o futuro será melhor, principalmente pelos aprendizados que acumulamos ao longo do primeiro ano de pandemia, e de que a educação, que já se apresenta sob a forma de ensino híbrido, irá superar as barreiras atuais, apresentamos as palavras de Freire (2016, p. 53):

Gosto de ser gente porque, mesmo sabendo que as condições materiais, econômicas, sociais e políticas, culturais e ideológicas em que nos achamos geram quase sempre barreiras de difícil superação para o cumprimento de nossa tarefa histórica de mudar o mundo, sei também que os obstáculos não se eternizam (FREIRE, 2016, p. 53).

\section{Considerações finais}

O ano de 2020 apresentou à escola novos desafios, a exemplo do acesso à internet por parte dos estudantes, necessária à participação nas aulas remotas; da flexibilização do currículo escolar; e do manuseio de novas tecnologias e aplicativos por parte dos docentes e discentes; mas também evidenciou um velho problema que se impõe como um grande desafio à educação brasileira: a histórica desigualdade social.

Ao avaliarmos o nível de participação dos estudantes, ao longo de 30 semanas de ensino remoto, ocorridas entre os meses de abril e dezembro de 2020, chegamos à conclusão de que, apesar de ser uma importante solução na tentativa de assegurar a instrução aos estudantes, o ensino remoto apresentou grandes limitações dentro de um contexto de vulnerabilidade social.

Para os mais entusiastas, foi, sem dúvida, um período de grande aprendizado. Contemplamos vários professores se familiarizando com os ambientes virtuais de aprendizagem e com toda a série de recursos que estes podem propiciar, sendo possível destacar os serviços de videochamada que, certamente, serão utilizados com uma frequência muito maior. Pelos estudantes, também é possível destacar avanços nesse sentido, ou seja, o ano de 2020 os colocou em contato com experiências que provavelmente seriam vivenciadas no final da presente década ou na próxima.

Todavia, cientes apenas do cenário exposto no parágrafo anterior, não acreditamos ser possível julgar o período de ensino remoto como sendo perfeitamente exitoso. Assistimos a um significativo processo de exclusão para o qual tentamos apresentar soluções, mas estas foram bastante tímidas. Obviamente, diante de um país com tamanha desigualdade, não caberia à escola resolver os problemas socioeconômicos anteriores à pandemia e agravados por esta, como o desemprego e a fome, que permeiam o universo escolar.

Portanto, acreditamos que as reflexões ora apresentadas podem servir de recursos para a elaboração de estratégias para a educação no pós-pandemia, de modo que, em todas as buscas por soluções apresentadas em um contexto em que ocorra dependência das tecnologias digitais, os envolvidos em tais propostas reflitam acerca do quantitativo de estudantes que podem ser excluídos no âmbito dessas deliberações.

\section{Referências}

ALBUQUERQUE, Larissa Cavalcanti de et al. Percepções discentes sobre aulas remotas em tempos de pandemia. Debates em Educação, v. 13, n. 31, p. 927-942, 2021. Disponível em: 
https://www.seer.ufal.br/index.php/debateseducacao/article/view/11739. Acesso em: 14 out. 2021.

ANDRADE, Natália Avilla. O ensino remoto como estratégia sazonal para a aprendizagem. Educar e evoluir, v. 1, n. 3, p. 13-17, jan. 2021. Disponível em: http://www.novageracaoeducacional.com.br/wp/wp-content/uploads/2021/01/Educar-eEvoluir-numero-3.pdf\#page=13. Acesso em: 22 jan. 2021.

ANJOS, Ricardo Eleutério. Base Nacional Comum Curricular e Educação Escolar de Adolescentes: Uma análise baseada na Pedagogia Histórico-Crítica e na Psicologia HistóricoCultural. In: MALANCHEN, Julia; MATOS, Neide da Silveira Duarte de; ORSO, Paulino José. A pedagogia histórico-crítica, as políticas educacionais e a Base Nacional Comum Curricular. Campinas: Autores Associados, 2020. p. 179-206.

BEHAR, Patrícia Alejandra. O ensino remoto emergencial e a educação a distância. Rio Grande do Sul: UFRGS, 2020. Disponível em: https://www.ufrgs.br/coronavirus/base/artigoo-ensino-remoto-emergencial-e-a-educacao-a-distancia/. Acesso em: 26 jan. 2021.

BELLONI, Maria Luiza. Educação a distância. 7. ed. Campinas: Autores Associados, 2015.

BEZERRA, Anselmo César Vasconcelos et al. Fatores associados ao comportamento da população durante o isolamento social na pandemia da COVID-19. Ciência \& Saúde Coletiva, Pré-print, Manuscript ID CSC 1079, 2020.

BRASIL. Decreto 9.057, de 25 de maio de 2017. Brasília: Ministério da Educação. Disponível em: http://www.planalto.gov.br/ccivil_03/_Ato20152018/2017/Decreto/D9057.htm\#art24. Acesso em: 26 jan. 2021.

BRANCO, Emerson Pereira et al. Evasão escolar: desafios para permanência dos estudantes na educação básica. Revista Contemporânea de Educação, v. 15, n. 34, 2020.

CAMPOS, Ricardo Bruno Cunha. Medo e estigma no contexto urbano contemporâneo: o bairro do Roger na cidade de João Pessoa - PB. Monografia (Bacharelado em Ciências Sociais) - Universidade Federal da Paraíba, João Pessoa, 2008. Disponível em: https://periodicos.ufpb.br/ojs2/index.php/caos/article/view/46943. Acesso em: 22 jan. 2021.

CANDAU, Vera Maria Ferrão. Ser professor/a hoje: novos confrontos entre saberes, culturas e práticas. Educação, Porto Alegre, v. 37, n. 1, p. 33-41, jan./abr. 2014.

CASTRO, Sirlene Rodrigues Ferreira. A infoexclusão escancarada pela COVID-19 e as atitudes professorais na perspectiva da sociologia das ausências e emergências. Revista de Estudos e Pesquisas sobre Ensino Tecnológico, v. 6, ed. esp. Desafios e avanços educacionais em tempos da COVID-19, 2020. Disponível em: http://200.129.168. 14:9000/educitec/index.php/educitec/article/view/1550. Acesso em: 26 jan. 2021.

FADANELLI, Eberson Luiz; PORTO, Ana Paula Teixeira. Cibercultura, tecnologias e exclusão digital. Literatura em debate, v. 14, n. 26, p. 33-44, 2020. Disponível em: http://revistas.fw.uri.br/index.php/literaturaemdebate/article/view/2407. Acesso em: 26 jan. 2021. 
FREIRE, Paulo. Pedagogia da autonomia: saberes necessários a prática educativa. São Paulo: Paz e Terra, 2016.

GUEDIN, Evandro; FRANCO, Maria Amélia Santoro. Questões de método na construção da pesquisa em educação. 2. ed. São Paulo: Cortez, 2011.

IBGE. Pesquisa Nacional por Amostra em Domicílio-Educação 2019. PNAD Contínua. Disponível em: https://agenciadenoticias.ibge.gov.br/media/com_mediaibge/arquivos/00e02 a8bb67cdedc4fb22601ed264c00.pdf. Acesso em: 19 jan. 2021.

MARCONI, Marina de Andrade; LAKATOS, Eva Maria. Metodologia científica. 6. ed. São Paulo: Atlas, 2011.

MASCARENHAS, Angela Cristina Belém. A contribuição do materialismo históricodialético para a análise das políticas educacionais. In: CUNHA, Célio da; SOUSA José Vieira de; SILVA, Maria Abádia da. O método dialético na pesquisa em educação. Campinas: Autores Associados, 2014. p. 177-182.

MENEZES, Lúcia Helena de Paula. Ser adolescente: entrelaçando afetividade, diálogo e grupo cultural de pertencimento. Revista Olhares e Trilhas, v. 4, n. 1, 2003.

MOORE, Michael G.; KEARSLEY, Greg. Educação a Distância: sistemas de aprendizagem on-line. 3. ed. São Paulo: Cengage Learning, 2013.

MORGADO, José Carlos; SOUSA, Joana; PACHECO, José Pacheco. Transformações educativas em tempos de pandemia: do confinamento social ao isolamento curricular. Revista Práxis Educativa, v. 15, p. 01-10, 2020.

NETTO, José Paulo. Introdução ao estudo do método de Marx. São Paulo: Expressão Popular, 2011.

PALLOFF, Rena M.; PRATT, Keith. O aluno virtual. Porto Alegre: Artmed, 2004.

PAULO, Jacks Richard; ARAÚJO, Stela Maris Medes Siqueira; OLIVEIRA, Priscila Daniele. Ensino remoto emergencial em tempos de pandemia: tecendo algumas considerações. Revista Dialogia, n. 36, p. 197-204, set./dez. 2020.

TRIVIÑOS, Augusto Nibaldo Silva. Introdução à pesquisa em ciências sociais. São Paulo: Atlas, 2015.

VALENTE, José Armando. Educação a distância: criando abordagens educacionais que possibilitam a construção de conhecimento. In: VALENTE, José Armando; MORAN, José Manuel; ARANTES, Valéria Amorim (org.). Educação a distância: pontos e contrapontos. São Paulo: Summus, 2011. p. 13-44.

Recebido em junho de 2021. Aprovado em outubro de 2021. 